\title{
COMMENT
}

Check for updates

\section{Communication is central to the mission of science}

\section{Sonia Contera}

The future of our species and planet hinges on our scientific creativity to tackle future challenges. However, the trust of the public in scientific processes needs to be earned and kept, which will require inclusive, self-reflecting, honest and inspiring science communication.

Many scientists, including myself, consider themselves to be important defenders of democracy and freedom, and regard science as one of the pillars of modern societies. Thus, we are flummoxed by the fact that people may support anti-scientific agendas. I often read in my social media feeds that some colleagues think (perhaps too naively) that such anti-scientific attitudes are irrational and inexplicable. By following anti-scientific discourses, people are often perceived by scientists as going against their own interests, for example, the anti-vaccine movement or climate change deniers. In this context, science communication often becomes an exercise to 'preach to the converted' and, in the worst case, may even be counterproductive; that is, providing ammunition for those arguing against science and 'experts'.

\section{Science and society are intertwined}

Science and the power it unleashes have been intermingled with class, gender, religion, national identity and the politics underlying social and economic dynamics ${ }^{1-3}$. Science not only provides technological tools to facilitate or counteract power relationships and geopolitical agendas, but it is also used for creating the narratives and cultural frameworks that justify the privileges enjoyed by those who benefit most from the deployment of technologies. Science's 'political capital' can be earned by both the oppressors and the oppressed and can be wielded either to promote democracy or to justify authoritarianism.

A classic example is the application of Darwin's theory of evolution to the social realm with the aim to promote the 'Social Darwinism' agenda (which was not intended by Darwin, although he asserted that women were at a lower stage of evolution $)^{4}$. Social Darwinists justify that the strong see their wealth and power increase, whereas the weak see theirs decrease, because of 'the natural order'. This ideology was presented as 'scientific fact' and was notoriously used (both by the left and right $)^{5}$ in the twentieth century to support authoritarianism, eugenics, sexism, racism, imperialism and fascism ${ }^{2-5}$. It is no surprise that people oppressed by these ideologies could be led to react against the science itself (not against its ideological misuse). For example, creationism incorrectly assumes that Social Darwinism is a logical consequence of the theory of Natural Selection in biology, thereby implying that scientists use their 'intelligentsia' status to marginalize the weakest in society. Rejection of science in general is also a rejection of its intrinsic capacity to improve fairness and democracy, and hence anti-scientific ideologies and technophobia can become powerful antidemocratic weapons.

In fact, the confusing dialectics between pro-science and anti-science politics has underpinned the rise of conspiracy theories during the COVID-19 crisis. Blaming $5 \mathrm{G}$ networks for the pandemic, or warning against nanobots that are secretly inserted in our bodies with the vaccine feed on collective fears that technology is used to control and even destroy the weak, while a powerful elite benefits from its rewards. Fear of nanobots is not new; 1990s' nanotechnology suffered a backlash in the public opinion following the publication of the book Engines of Creation by K. Eric Drexler. In this book, the author speculated about a global apocalyptic scenario brought about by self-replicating nanomachines. This 'grey goo' prospect led to the development of the first 'responsible research and innovation' policies, which have succeeded in building trust in nanotechnology. This trust will hopefully be reinforced by the new nanotechnology-based COVID-19 vaccines.

\section{Creating a conversation}

The aforementioned narratives of 'scientific elitism' do not reflect reality. Some scientists may be motivated by power, status and wealth; however, most of us become scientists out of a vocation to work for the common good and to pursue knowledge that facilitates human advancement. In an unequal world, scientific careers are also becoming degraded and increasingly precarious, which will lead to social and political consequences that are yet to unfold.

This is a complex, ambivalent scenario full of possibilities for human progress and equality enabled by science; however, it also presents the threat of a dystopian future for the democratic process. In societies, in which the lives of citizens are increasingly determined 
by technology and science, trust in scientific governance becomes a fundamental pillar of the democratic system itself. Citizens' trust in the democratic process will be eroded if the benefits of science and technologies are not fairly distributed, and if unaccountable technological powers take control of much of our lives. As scientists, we need to learn how to navigate this political minefield. Democracy and the future of our planet, which faces potentially catastrophic consequences of global warming, are in danger if a large number of citizens turn their backs on science. Therefore, it is imperative to engage in a dialogue to enable societies to democratically decide how to deploy science for the benefit of all, not just for the powerful, educated and well-connected ${ }^{6}$. How can we generate a healthy trust in science? Let me propose a few ideas that might be useful when you communicate a scientific story.

\section{Communicate your scientific story}

Investigate the origins. Where does the idea come from, who were the authors, and what were their agendas? Are there untold stories? Are there forgotten people, who have been left out of the story because of their socioeconomic status, gender or race? In my own experience, by expounding its context, scientific discovery becomes a human story, which people can relate to and establish a dialogue with. You may discover terrible contradictions; for example, bad people can produce good science or good science and scientists may have been used for despicable purposes. Expose the power dynamics that underlie the misuse of science, then counteract by imagining how science can be turned into something that positively affects lives.

Disclose your own agenda and position. Why are you communicating this? What do you, your organization and/or group gain from it? Reflect on your biases, how your gender and socioeconomic status affect your judgement and intention. People will notice your biases, even if you don't.

Inspire your audience and yourself. Identify potential applications or ramifications of the science or technologies, and how they may enable creativity and the birth of new scientific, cultural or social spaces.

Explore the positive scenarios. Climate change deniers have been shown to act more pro-environmentally in situations, in which they have been proposed climate change action that can facilitate the creation of a more considerate and caring society, and lead to greater economic and technological development ${ }^{7}$. In this case, seeing that political action to improve social outcomes accompanies climate change mitigation builds support for the science.

Investigate unintended consequences. Consider unintended consequences, in particular, for the weakest in society. How can we anticipate and mitigate risks? Consider if members of your audience have been affected in the past by the science you are explaining, or how they may be affected in the future. For example, the legacy of exploitative medical research affecting Black people in the USA may now contribute to COVID-19 vaccine hesitancy ${ }^{8}$.
Adapt your language. Consider your language to maximize the usefulness of the information. Being aware of language and terminology also helps to improve your own understanding of the topic; by switching from 'scientific slang' to more standard speech, you can identify the biases of your own field and realize possibilities that are not apparent within the 'scientists' bubble'.

Contribute to the democratic process. Don't forget that science communication should be a contribution to the democratic process; that is, its purpose is not to convince people to accept science as dogma. Especially in complex matters, such as climate science, biology or medicine, which affect the present and future, hopes and fears of everyone, it is important to recognize that our knowledge is constantly evolving and refined. Expose the weaknesses and strengths of your analysis with honesty and with the best scientific knowledge available. Learn the lessons from the COVID-19 pandemic: science communication has been and continues to be key in the management of the pandemic ${ }^{8,9}$. Controversial political decisions (for example, lockdowns, or the confinement of people to care homes), which restrict the human rights of citizens, are being made taking into account scientific advice. This decision-making process will surely be the subject of future enquires from which we will all have to learn important lessons. Similarly, for the successful deployment of vaccination campaigns, it is key to fully disclose the process and outcomes of clinical trials, as well as side effects of the vaccines, and to explain the technologies and be mindful of social disparities ${ }^{8-10}$.

\section{Trust in science}

Inclusive, reactive, self-reflecting and inspiring science communication should become central to the mission of science; we must find effective ways to embed communication in our scientific practice in a way that enhances democracy and equality. Generating trust in science needs honesty, transparency and a genuine intention to apply science for the common good. It requires humility to engage with other points of view and to acknowledge that in a democracy, science is not an external force acting on society but a product of its complexity.

1. Foucault, M. The Order of Things: Archaeology of the Human Sciences (Routledge, 2001).

2. Feyerabend, P. Science in a Free Society (Verso, 1978).

3. Saini, A. Superior: The Return of Race Science (4th State, 2018).

4. Saini, A. Inferior: How Science Got Women Wrong-and the New

Research That's Rewriting the Story (4th State, 2017).

5. Gould, S. J. Let's Leave Darwin Out of It. New York Times (21 May 1998).

6. Contera, S. Nano comes to life: how nanotechnology is transforming medicine and the future of biology. 171-187 (Princeton University Press, 2019).

7. Bain, P., Hornsey, M. \& Bongiorno, R. et al. Promoting proenvironmental action in climate change deniers. Nat. Clim. Change 2, 600-603 (2012).

8. Subbaraman, $\mathrm{N}$. This COVID-vaccine designer is tackling vaccine hesitancy - in churches and on Twitter. Nature 590, 377 (2021).

9. Kimberly, H., Nguyen, K. H. \& Srivastav, A. et al. COVID-19 vaccination intent, perceptions, and reasons for not vaccinating among groups prioritized for early vaccination - United States, September and December 2020. Morb. Mortal. Wkly. Rep. 70, 217-222 (2021).

10. Ball, P. Anti-vaccine movement could undermine efforts to end coronavirus pandemic, researchers warn. Nature 581, 251 (2020).

\section{Competing interests}

The author declares no competing interests. 